\title{
Planned Start of Assessment Interval
}

National Cancer Institute

\section{Source}

National Cancer Institute. Planned Start of Assessment Interval. NCI Thesaurus. Code C117061.

The period of time that the assessment, done over an interval of time, is intended to begin. 